\title{
Mobile TV as a Marketing Tool in South Africa: A Consumer's Perspective
}

\author{
Tinashe Chuchu \\ Department of Marketing, University of the Witwatersrand \\ Email: tinashechuchu@yahoo.com \\ Norman Chiliya \\ Department of Marketing, University of the Witwatersrand, Private Bag 3, Wits, 2050 \\ Email: norman.chiliya@wits.ac.za \\ Lloyd Uta \\ Department of Marketing, University of the Witwatersrand \\ Email: kudzanai.uta@gmail.com
}

Doi:10.5901/mjss.2014.v5n25p158

\begin{abstract}
Mobile Television is highly considered to be the next breakthrough application in wireless technology. Recently mobile marketing has become an important method of communication with the recent advances in mobile phone technology. The primary objective of the study was to find solutions that could possibly increase the number of mobile TV subscribers in South Africa so as to increase mobile TV usefulness as a marketing tool for products and services. The design of the study was a quantitative design. This research involved distributing a questionnaire at The University of The Witwatersrand to a sample group of 380 students between the ages of 18 to 25. The data collected was analysed using Statistical Analysis Software (SAS) Enterprise Guide 5.The results of the empirical study indicated that size of screens being too small was a major concern for mobile TV viewers and would make viewers less likely consider viewing mobile TV.
\end{abstract}

Keywords: Mobile television, technology, communication

\section{Introduction}

Mobile television has evolved into a marketing vehicle due to recent technological advances in mobile devices (Varnali \& Toker, 2009). Mobile TV can be defined as television content which can be viewed on mobile devices through the use of wireless networks (Shim, Ahn \& Shim, 2006). There are various standards for Mobile TV networks, including T-DMB (Terrestrial-Digital Multimedia Broadcasting), ISDB-T (Integrated Services Digital Broad-casting-Terrestrial) and DVB-H (Digital Video Broadcasting- Handheld) (Hsu \& Hefeeda, 2009). This research paper explored the (DVB-H) which is the abbreviation for Digital Video Broadcasting-Handheld and (DMB) which stands for Digital Multimedia Broadcasting and has been used to a greater extent Europe and Asia (Cullen, 2005).

According to (Cullen, 2005) mobile TV is a service that will be the next milestone for the wireless industry. The mobile industry in Africa is on the rise, leading the way is South Africa which boasts a $6 \%$ stake of all of Africa's mobile usage (BBC News Africa, 2011). DStv Mobile, a division of Multichoice had been pioneering the way for mobile TV in South Africa and had introduced mobile TV for smartphones on the $23^{\text {rd }}$ of November 2010 for a monthly subscription fee of R36. Another mobile TV device Multichoice introduced was the DStv Drifta, launched in 2011 it sales for R449 and has a subscription fee of R49 per month. The Drifta is a mobile TV device that receives a DVB-H signal which it then turns into a wireless fidelity (Wi-Fi) signal which then enables wireless devices such as laptops, tablets and smartphones to receive television signals.

The Drifta needs to be within range of the DVB-H coverage area for it to work. The Drifta can also be connected through a Universal Serial Bus (USB) of a laptop or personal computer (Multichoice.com, 2013). On the $7^{\text {th }}$ of September 2012, the DStv Walka which is the company's latest mobile TV device was released and was being sold for R499 (Multichoice.com, 2013). The future for mobile TV in South Africa seems to be bright when one looks at the penetration figures of television which is viewed by $76 \%$ of all South African households and $58 \%$ of all them already subscribe to pay 
TV and generate an estimated US\$1.9 billion (Engineering News, 2013). The research involved quantitative techniques. A comprehensive research questionnaire was developed and distributed to respondents to determine the impact that Mobile TV had in South Africa. MultiChoice's DStv Mobile has utilized both broadcast and streaming technology to provide mobile TV, that is Digital Video Broadcasting (DVB-H) and Third Generation (3G) streaming respectively (Multichoice.com, 2013).

\subsection{Problem Statement}

Knoche, McCarthy \& Sasse (2005) conducted a study to find out complaints customers had about mobile TV. According to their findings, users were not comfortable operating handheld televisions as they had to be operated $15 \mathrm{~cm}$ away from the viewer's eyes, which respondents considered to be too close for enjoyment. Knoche et al., (2005) also found that people had discomfort with the smallness of the screens fearing eye strain age, poor coordination between audio and sound which would possibly prevent them from indulging further in mobile TV. The desired viewing distance for maximum pleasure and comfort is considered to be $89 \mathrm{~cm}$ (Knoche et al, 2005). Often mobile users want the largest screens possible for viewing but still want their phones to remain small which makes it fairly difficult to determine the most appropriate sizes for handheld devices (Knoche et al, 2005).

The purpose of this research was to explore the perceptions and attitudes towards causes of low adoption levels of mobile TV in South Africa. This study intended to find ways of using mobile TV as a marketing tool for products and services in South Africa. The primary objective of the study was to find solutions that could possibly increase the number of mobile TV subscribers in South Africa so as to increase mobile TV usefulness as a marketing tool for products and services.

\subsection{Proposed Theoretical Model and Hypotheses}

In-order to determine the perceptions that consumers in South Africa had towards mobile TV being used as a marketing tool by marketers a modified Technology Acceptance Model was used as a basis for this study. This model contains the following independent variables; experience, user's perceptions on mobile TV, image, screen size, functionality, convenience, and output quality. The dependent variable was the acceptance of mobile TV. The hypotheses were dependent on consumer's acceptance of mobile TV. For purposes of the study the researchers used a modified hypothesized Technology Acceptance model that was adopted from Venkatesh \& Davis (2000).

Figure 1: Modified Hypothesized Technology Acceptance Model

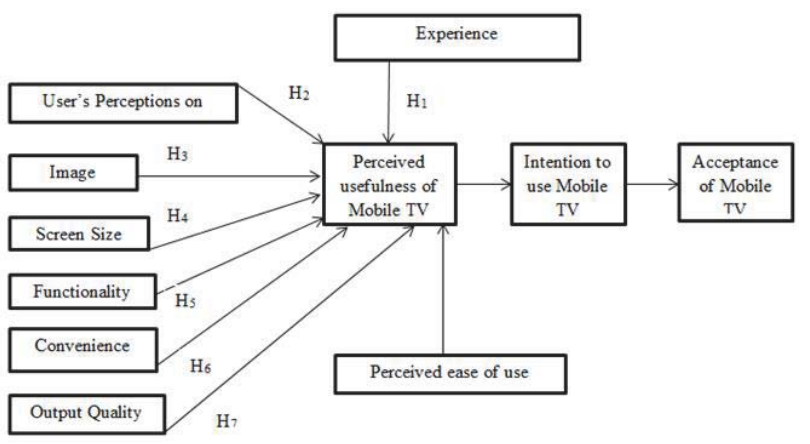

Adopted from Venkatesh \& Davis (2000)

\subsection{Hypotheses}

Hypothesis 1: Mobile TV experience is positively related to adoption.

Hypothesis 2: The user's perception of mobile TV has a positive relationship with the mobile TV acceptance.

Hypothesis 3: The image associated with owning or using mobile TV is positively related to mobile TV acceptance.

Hypothesis 4: The size of the screen has a positive relationship with the adoption of mobile TV

Hypothesis 5: Mobile TV functionality is positively related to the acceptance of mobile TV. 
Hypothesis 6: Mobile TV convenience is positively related to acceptance.

Hypothesis 7: Output quality is positively related to adoption of mobile TV.

\section{Research Design and Methodology}

The following section outlines the research design and the methodology used for this study.

\subsection{Research Design}

Research design helps to map out procedures for gathering information that is required to and solve given problems (Malhotra \& Birks, 2007). The research design establishes the foundation for the entire research project (Malhotra \& Birks, 2007). The design of the study was quantitative, non-experimental and correlation design. Five point likert -scales were used to collect data from respondents in order to determine their preferences and attitudes towards mobile television. To collect data from respondents for this study a self-administered research questionnaire was distributed to participants by the researchers.

\subsection{Sample Size Determination}

According to (Lenth, 2001) sample size determination is crucial in planning a statistical study as well as challenging. The sample size was determined using the Raosoft sample size calculator. Raosoft is statistical software that is used to calculate sample size. Raosoft takes into the following factors; account the margin of error, the confidence level, the population size and the response distribution. The researchers chose the default settings on Raosoft which had a margin of error at 5\%, confidence level at $95 \%$ sample size at 30000 and a response distribution of $50 \%$. The calculated sample size was 380 respondents.

\section{Results}

The first linear regression analysis tested the relationship between the effect of mobile TV experience and the acceptance of mobile TV by consumers. Below are the null and alternate hypotheses. The significance level that was used for the linear regression analysis was (a) 0.005 .

$\mathrm{H} 1$ : Mobile TV experience is positively related to adoption.

Table 1: Linear regression analysis test for the experience obtained from mobile TV usage

\begin{tabular}{|c|c|c|c|c|c|}
\hline \multicolumn{7}{|c|}{ Analysis of Variance } \\
\hline Source & DF & Sum of squares & Mean Squares & F Value & Pr>F \\
\hline Model & 1 & 0.59912 & 0.59912 & 1.03 & 0.3105 \\
\hline Error & 247 & 143.27655 & 0.58007 & & \\
\hline Corrected total & 248 & 143.87566 & & & \\
\hline \multicolumn{7}{|c|}{} & Coeff Var & Root MSE & Dependent Mean & R-Square \\
\cline { 2 - 6 } & 22.60893 & 0.76162 & 3.36867 & 0.0042 \\
\hline \multicolumn{7}{|c|}{ Parameter Estimates } & t Value & Pr $>|t|$ \\
\hline Variable & DF & Parameter Estimate & Standard Error & 12.32 & $<.0001$ \\
\hline Intercept & 1 & 3.11638 & 0.25290 & 1.02 & 0.3105 \\
\hline Average Experience & 1 & 0.07760 & 0.07635 & &
\end{tabular}

The P-value for the experience variable is 0.3105 ; this is significant at the 0.05 significance level. Therefore the researchers failed to reject the null hypothesis that states which states that the perceived experience obtained from mobile TV is not significantly related to acceptance and rejects the alternative hypothesis which states that the perceived experience obtained from mobile TV is positively related to acceptance. This means that viewers' perceive the experience obtained from mobile TV to be of no significance implying that viewers are less likely to accept mobile TV. This ultimately meant that viewers could not see the value of mobile TV and hence are less motivated to view mobile TV. 


\subsection{Linear regression for the Perceptions construct}

The second linear regression analysis tested the relationship between the viewer's perceptions of mobile TV and the viewer's acceptance of mobile TV. Below are the null and alternate hypotheses. The significance level that was used for the linear regression analysis was (a) 0.005 .

H2: The user's perception of mobile TV has a positive relationship with the mobile TV acceptance.

Table 2: Linear regression analysis test for user's perceptions towards mobile TV

\begin{tabular}{|c|c|c|c|c|c|}
\hline \multicolumn{7}{|c|}{ Analysis of Variance } \\
\hline Source & DF & $\begin{array}{c}\text { Sum of } \\
\text { Squares }\end{array}$ & $\begin{array}{c}\text { Mean } \\
\text { Squares }\end{array}$ & F Value & Pr $>$ F \\
\hline Model & 1 & 34.06731 & 34.06731 & 70.97 & $<.0001$ \\
\hline Error & 378 & 181.44795 & 0.48002 & & \\
\hline Corrected total & 379 & 215.51526 & & & R-Square \\
\hline \multicolumn{7}{|c|}{} & CoeffVar & Root MSE & $\begin{array}{c}\text { Dependent } \\
\text { Mean }\end{array}$ & Parameter Estimates \\
\cline { 2 - 6 } & 20.77960 & 0.69284 & 3.33421 & 0.1581 \\
\hline Variable & \multirow{2}{*}{ DF } & $\begin{array}{c}\text { Parameter } \\
\text { Estimate }\end{array}$ & $\begin{array}{c}\text { Standard } \\
\text { Error }\end{array}$ & tValue & Pr $>|t|$ \\
\hline Intercept & 1 & 1.73662 & 0.19294 & 9.00 & $<.0001$ \\
\hline Average Perceptions & 1 & 0.49101 & 0.05828 & 8.42 & $<.0001$ \\
\hline
\end{tabular}

The $p$-value for the perceptions construct is <.0001. This is less than the level of significance (a) 0.05 hence the null hypothesis is rejected which states viewers perceptions of mobile TV are not significantly related to the acceptance of mobile TV in favour of the alternative hypothesis which states that viewers' perceptions of mobile TV are positively related to mobile TV acceptance. This implied is that if respondents have positive perceptions towards mobile TV they would in turn accept mobile TV. Television viewers were more willing to view mobile TV if they had positive perceptions about mobile TV.

\subsection{Linear regression for the Image construct}

The third linear regression analysis tested the relationship between the image associated with owning or using mobile TV and viewers acceptance mobile TV.Below are the null and alternative hypotheses. The significance level that was used for the linear regression analysis was (a) 0.005 .

H3: The image associated with owning or using mobile TV is positively related to mobile TV acceptance.

Table 3: Linear regression analysis test for the Image associated with mobile TV

\begin{tabular}{|c|c|c|c|c|c|}
\hline \multicolumn{6}{|c|}{ Analysis of Variance } \\
\hline Source & DF & $\begin{array}{l}\text { Sum of } \\
\text { Squares }\end{array}$ & $\begin{array}{c}\text { Mean } \\
\text { Squares }\end{array}$ & F Value & $\operatorname{Pr}>\mathrm{F}$ \\
\hline Model & 1 & 6.32920 & 6.32920 & 11.44 & 0.0008 \\
\hline Error & 378 & 209.18607 & 0.55340 & & \\
\hline Corrected total & 379 & 215.51526 & & & \\
\hline & & CoeffVar & Root MSE & $\begin{array}{l}\text { Dependent } \\
\text { Mean }\end{array}$ & R-Square \\
\hline & & 22.31143 & 0.74391 & 3.33421 & 0.0294 \\
\hline \multicolumn{6}{|c|}{ Parameter Estimates } \\
\hline Variable & DF & $\begin{array}{l}\text { Parameter } \\
\text { Estimate }\end{array}$ & $\begin{array}{l}\text { Standard } \\
\text { Error }\end{array}$ & tValue & $\operatorname{Pr}>|t|$ \\
\hline Intercept & 1 & 2.86946 & 0.14263 & 20.12 & $<.0001$ \\
\hline Average Image & 1 & 0.16407 & 0.04852 & 3.38 & 0.0008 \\
\hline
\end{tabular}

The P-value for the image variable was 0.0008 this is significant at the 0.05 significance level therefore the null 
hypothesis is rejected which states that the perceived image associated with mobile TV is not significantly related to the acceptance of mobile TV in favour of the alternative hypothesis which states that the image associated with mobile TV is positively related to the acceptance of mobile TV. This means that if viewer's associate mobile TV ownership or mobile TV use with an improved image they would be more willing to accept mobile TV.

\subsection{Linear regression for the Screen size construct}

The fourth linear regression analysis tested the relationship between the mobile TV screen size and the acceptance mobile TV. Below are the null and alternate hypotheses. The significance level that was used for the linear regression analysis was (a) 0.005 .

H4: The size of the screen has a positive relationship with the adoption of mobile TV

Table 4: Linear regression analysis test for Screen size associated with mobile TV

\begin{tabular}{|c|c|c|c|c|c|}
\hline \multicolumn{7}{|c|}{ Analysis of Variance } \\
\hline Source & DF & $\begin{array}{c}\text { Sum of } \\
\text { Squares }\end{array}$ & $\begin{array}{c}\text { Mean } \\
\text { Squares }\end{array}$ & F Value & Pr>F \\
\hline Model & 1 & 0.34045 & 0.34045 & 0.60 & 0.4398 \\
\hline Error & 378 & 215.17482 & 0.56925 & & \\
\hline Corrected total & 379 & 215.51526 & & & \\
\hline \multicolumn{7}{|c|}{ CoeffVar } & Root MSE & $\begin{array}{c}\text { Dependent } \\
\text { Mean }\end{array}$ & R-Square \\
\cline { 3 - 6 } & 22.62855 & 0.75448 & & 0.0016 \\
\hline \multicolumn{7}{|c|}{ Parameter Estimates } \\
\hline Variable & DF & $\begin{array}{c}\text { Parameter } \\
\text { Estimate }\end{array}$ & $\begin{array}{c}\text { Standard } \\
\text { Error }\end{array}$ & tValue & Pr > |t| \\
\hline Intercept & 1 & 3.44867 & 0.15299 & 22.54 & $<.0001$ \\
\hline Average Screen size & 1 & -0.04107 & 0.05311 & -0.77 & 0.4398 \\
\hline
\end{tabular}

The $P$ value for the image variable is 0.4398 , this is insignificant at the 0.05 significance level hence the researchers failed to reject the null hypothesis which states that mobile TV screen size is not significantly related to the acceptance of mobile TV. This means is that the screen sizes of mobile TV makes no difference in the viewer's mind as to whether the viewer would accept mobile TV or not. This would probably imply that for the various mobile TV screen sizes that are available consumers perceive them to be equal in terms of the amount of material they could show.

\subsection{Linear regression for the Functionality construct}

The fifth linear regression analysis tested the relationship between mobile TV functionality and the acceptance of mobile TV. Below are the null and alternate hypotheses. The significance level that was used for the linear regression analysis was (a) 0.005 .

H5: Mobile TV functionality is positively related to the acceptance of mobile TV.

Table 5: Linear regression analysis test for Functionality associated with mobile TV

\begin{tabular}{|c|c|c|c|c|c|}
\hline \multicolumn{6}{|c|}{ Analysis of Variance } \\
\hline Source & DF & $\begin{array}{c}\text { Sum of } \\
\text { Squares }\end{array}$ & $\begin{array}{c}\text { Mean } \\
\text { Squares }\end{array}$ & F Value & Pr $>$ F \\
\hline Model & 1 & 5.19843 & 5.19843 & 9.34 & 0.0024 \\
\hline Error & 378 & 210.31683 & 0.55639 & & \\
\hline Corrected total & 379 & 215.51526 & & & \\
\hline \multicolumn{7}{|c|}{} & CoeffVar & Root MSE & $\begin{array}{c}\text { Dependent } \\
\text { Mean }\end{array}$ & R-Square \\
\cline { 3 - 6 } & 22.37165 & 0.74592 & 3.33421 & 0.0241 \\
\hline \multicolumn{7}{|c|}{ Parameter Estimates } \\
\hline Variable & DF & $\begin{array}{c}\text { Parameter } \\
\text { Estimate }\end{array}$ & $\begin{array}{c}\text { Standard } \\
\text { Error }\end{array}$ & tValue & Pr > |t| \\
\hline Intercept & 1 & 2.76732 & 0.18937 & 14.61 & $<.0001$ \\
\hline Average Functionality & 1 & 0.18916 & 0.06189 & 3.06 & 0.0024 \\
\hline
\end{tabular}


The $P$ value for the functionality variable is 0.0024 this is significant at the $5 \%$ significance level hence the null hypothesis is rejected which states that that Mobile TV functionality is not significantly related to the acceptance of mobile TV in favour of the alternative hypothesis which states that mobile TV functionality has a positive relationship with the acceptance of mobile TV. What this means is that mobile TV functions have a positive relationship with the acceptance of mobile TV. This means that if viewers perceive mobile TV functions to be easy to understand and use, they would be more willing to accept mobile TV.

\subsection{Linear regression for the Convenience construct}

The linear regression analysis is testing the relationship between mobile TV convenience and the acceptance of mobile TV. Below are the null and alternate hypotheses. The significance level that was used for the linear regression analysis was (a) 0.005 .

H6: Mobile TV functionality is positively related to the acceptance of mobile TV.

Below is the table illustrating the linear regression analysis for the convenience construct.

Table 6: Linear regression analysis test for Convenience associated with mobile TV

\begin{tabular}{|c|c|c|c|c|c|}
\hline \multicolumn{6}{|c|}{ Analysis of Variance } \\
\hline Source & DF & $\begin{array}{c}\text { Sum of } \\
\text { Squares }\end{array}$ & $\begin{array}{c}\text { Mean } \\
\text { Squares }\end{array}$ & F Value & Pr>F \\
\hline Model & 1 & 40.76228 & 40.76228 & 88.17 & $<.0001$ \\
\hline Error & 378 & 174.75298 & 0.46231 & & \\
\hline Corrected total & 379 & 215.51526 & & & \\
\hline \multicolumn{7}{|c|}{} & Coeff Var & Root MSE & $\begin{array}{c}\text { Dependent } \\
\text { Mean }\end{array}$ & R-Square \\
\cline { 2 - 6 } & 20.39264 & 0.67993 & 3.33421 & 0.1891 \\
\hline \multicolumn{7}{|c|}{ Parameter Estimates } \\
\hline Variable & DF & $\begin{array}{c}\text { Parameter } \\
\text { Estimate }\end{array}$ & $\begin{array}{c}\text { Standard } \\
\text { Error }\end{array}$ & t Value & Pr > $|\mathrm{t}|$ \\
\hline Intercept & 1 & 2.15814 & 0.13001 & 16.60 & $<.0001$ \\
\hline Average Convenience & 1 & 0.40806 & 0.04346 & 9.39 & $<.0001$ \\
\hline
\end{tabular}

The $P$ value for the convenience variable is 0.0024 this is significant at the $5 \%$ significance level hence the null hypothesis is rejected which states that mobile TV convenience is not significantly related to the acceptance of mobile TV in favour of the alternative hypothesis which states that mobile TV convenience is positively related to acceptance of mobile TV. This means that if viewers perceive mobile TV to be convenient they would be willing to accept mobile TV.

\subsection{Linear regression for the Output quality construct}

The linear regression analysis tested the relationship between mobile TV output quality and the acceptance of mobile TV. Below are the null and alternate hypotheses. The significance level that was used for the linear regression analysis was (a) 0.005 .

H7: Output quality is positively related to adoption of mobile TV. 
Table 7: Linear regression analysis test for Output quality associated with mobile TV

\begin{tabular}{|c|c|c|c|c|c|}
\hline \multicolumn{6}{|c|}{ Analysis of Variance } \\
\hline Source & DF & $\begin{array}{c}\text { Sum of } \\
\text { Squares }\end{array}$ & $\begin{array}{c}\text { Mean } \\
\text { Squares }\end{array}$ & F Value & Pr>F \\
\hline Model & 1 & 30.87520 & 30.87520 & 63.21 & $<.0001$ \\
\hline Error & 378 & 184.64007 & 0.48847 & & \\
\hline Corrected total & 379 & 215.51526 & & & \\
\hline \multicolumn{7}{|c|}{ CoeffVar } & Root MSE & $\begin{array}{c}\text { Dependent } \\
\text { Mean }\end{array}$ & R-Square \\
\cline { 2 - 6 } & 20.96158 & 0.69890 & 3.33421 & 0.1433 \\
\hline \multicolumn{7}{|c|}{ Parameter Estimates } \\
\hline Variable & DF & $\begin{array}{c}\text { Parameter } \\
\text { Estimate }\end{array}$ & $\begin{array}{c}\text { Standard } \\
\text { Error }\end{array}$ & tValue & Pr > |t| \\
\hline Intercept & 1 & 2.08169 & 0.16157 & 12.88 & $<.0001$ \\
\hline Average Output quality & 1 & 0.43770 & 0.05505 & 7.95 & $<.0001$ \\
\hline
\end{tabular}

The $P$ value for the output quality variable is $<.0001$ this is significant at the $5 \%$ significance level hence the null hypothesis is rejected which states that Mobile TV output quality is not significantly related to the acceptance of mobile TV in favour of the alternative hypothesis which states mobile TV output quality is positively related to acceptance. What this means is that if viewers perceive mobile TV output quality to be favourable they would be more willing to accept mobile TV.

\section{Findings}

This research comprised of seven main findings which encompassed the perceptions that television viewers in South Africa had about mobile TV being used as a marketing tool for products and services. This study was based on a modified technology acceptance model. This model was used to explain and predict user acceptance of new technology (Venkatesh \& Davis, 2000). This modified technology acceptance model had eight constructs which were tested and these included: experience, user's perceptions, image, screen size, functionality, convenience, output quality and acceptance of mobile TV. The study also looked at how viewers perceived the relationship that existed or potentially existed between each construct and acceptance.

\subsection{Perceived Experience of Mobile TV}

The first finding of the study was that the perceived experience obtained from mobile TV was not significantly related to acceptance. What this means is that respondents perceived the experience obtained from mobile TV to be of no significance implying that they were less likely to accept mobile TV. This ultimately meant that viewers could not see the value of mobile TV and hence were less motivated to view mobile TV. This meant that viewers were not willing to substitute traditional TV for mobile TV.

\subsection{Perceptions about Mobile TV}

The second finding of this study was that viewers' perceptions about mobile TV were positively related to mobile TV acceptance. What this implied was that if respondents have positive perceptions towards mobile TV they would in turn accept mobile TV. Television viewers were more willing to view mobile TV if they had positive perceptions about mobile TV. This finding was supported by a study conducted by (Ali, 2007). Ali (2007) established that television viewers were not prepared to replace their traditional television sets with mobile TV as they considered mobile TV to be merely a convenient tool for television viewing but not a device they would be willing to entirely substitute for traditional television.

\subsection{Perceived image of Mobile TV}

The third finding of this study was that the perceived image associated with mobile TV was positively related to the acceptance of mobile TV. This meant that if respondents associated mobile TV ownership or use with an improved image they would be more willing to accept mobile TV. Viewers were more likely to watch mobile TV if they believed it would 
raise their image in society. Hazel Kwon, Kyounghee, and Bum Soo Chon (2009) also believe that mobile T.V adoption is heavily influenced by the social image that the consumers are looking to portray of themselves which suggests that these devices should be customized well in order to suit the relevant image and personalities of the potential users.

Screen size of Mobile TV

The fourth finding of this study was that that mobile TV screen size was not significantly related to the acceptance of mobile TV.What this means is that the screen sizes of mobile TV made no difference in the viewer's mind as to whether the viewer would accept mobile TV or not. This probably implied that for the various mobile TV screen sizes that are available consumers perceived them to be equal in terms of the amount of material they could show and therefore no mobile TV screen size would influence the viewer to accept mobile TV. This finding was supported by Marcus, Roibas, \& Sala (2010) who pointed that mobile TV screens where too small and not suited for showing television content.

\subsection{Perceived Functionality of Mobile TV}

The fifth finding of this study was that that mobile TV functionality had a positive relationship with the acceptance of mobile TV. This means is that if viewers perceive mobile TV functions to be easy to understand and use, they would be more willing to accept mobile TV. Carlsson \& Walden (2007) support this finding as their study also established that mobile TV services should be simple to understand and easy to use.

\subsection{Perceived Convenience of Mobile TV}

The sixth finding of this study was that mobile TV convenience is positively related to the acceptance of mobile TV. This means that if viewers perceive mobile TV to be convenient they would therefore be more likely to accept mobile TV.

\subsection{Perceived Output Quality of mobile TV}

The seventh finding of this study was that mobile TV output quality is positively related to acceptance. What this meant was that if viewers perceived mobile TV output quality to be favourable they would be more willing to accept mobile TV.

\section{Recommendations and Marketing implications}

There is therefore need for marketers to demonstrate the benefits associated with the adoption of Mobile T.V through marketing campaigns in order to convince consumers to perceive mobile TV as an informative media platform. Marketers should also convince viewers that mobile TV has the potential to revolutionize the way viewers enjoy entertainment. Another implication for marketing managers is that if marketing managers decide to use mobile TV devices and services as marketing tools they have to first of all take screen size into consideration as results of the empirical study revealed that size of screens being too small was a major concern for mobile TV viewers and would make viewers less likely to consider viewing mobile TV. This finding was supported by study by Knoche et al, (2005) who stated that viewers complained about the discomfort of viewing television content on mobile TV. A solution to this problem was suggested by Knoche et al, (2005), who proposed that increasing the number of pixels in images would possibly increase the perceived quality of mobile TV. Pixels are dots per inch that assemble a picture (Knoche et al, 2005). This implied that marketing managers should provide mobile TV images in marketing campaigns that contain a high number of pixels in order to assure high picture quality thereby reducing the discomfort associated with viewing mobile TV. The researchers would recommend South African marketing managers to conduct a research on mobile TV perceptions within a South African context on a larger scale than as of this study. This would possibly overcome the limitations of this research such as a restricted sample size, low funding and limited time. If marketers have a substantial budget appropriated to investigating the perceptions of South African viewers towards mobile TV they would be able to successfully implement marketing strategies that would enable them to raise the awareness and penetration levels of mobile TV in South Africa. Investing a substantial amount of resources such as time, money and labour in researching on mobile TV consumption in South Africa would enable marketers to know how, when and why they should introduce mobile TV to a particular target market? Marketers would also save money in the actually implementation of mobile TV as a marketing tool for products and services if thorough research on consumer perceptions is conducted. 


\section{Limitations of the Study and Future Research}

In conducting this study there were many limitations that included small sample size, time and financial constraints. Due to the fact that only students who attend at the University of The Witwatersrand were selected for the study it meant that the study left other viewers of mobile TV who did not attend at The University of the Witwatersrand thereby under representing the number of possible mobile TV users that could have been used for the study. This also meant that the perceptions of those mobile TV viewers who could not be reached were not included in the research and therefore this compromised the full extent of what the study could have achieved. Future research should therefore consider making use of different population samples in order to ensure that the study truly represents the perceptions and attitudes that the South African population has on mobile television. Future researchers may also consider evaluating the type of programs that are best suited for Mobile T.V in order to make them more accessible on these media channels as this will go a long way in helping to alter the attitudes that most consumers have of Mobile T.V.

\section{Conclusion}

The contribution of this study was to find ways of increasing the penetration levels of mobile TV in South Africa as well as using prospects' and consumers' perceptions of mobile TV to find ways of implementing mobile TV as a marketing tool for products and services in South Africa. Marketers and managers could possibly make the initiative of raising mobile TV awareness levels in South Africa through taking the findings of this research into consideration. Based on the results of the findings of this study the researchers were able to draw a conclusion on the perceptions that South African television viewers have about mobile TV. Based on the findings that pertained to experience of mobile TV the researchers found that viewers were not inclined towards accepting mobile TV as they considered the mobile TV experience to be of no value. The objective of this study was to find if mobile TV could be used as a marketing tool in South Africa and based on the findings of this research mobile TV marketing is not a viable business idea unless if consumer's perceptions towards mobile TV become more positive and further developments are undertaken by mobile TV service providers to improve mobile TV devices and mobile TV services then mobile TV could become a plausible marketing communications tool.

\section{References}

Ali, S. (2007). Upwardly mobile: a study into mobile TV use amongst children. Young Consumers: Insight and Ideas for Responsible Marketers, 8(1), 52-57.

BBC NEWS AFRICA, (2011) Africa's mobile phone industry 'booming [Online] Available: http:// www.bbc.co.uk/news/world-africa15659983 (April 14, 2013)

Carlsson, C., \& Walden, P. (2007, January). Mobile TV-to live or die by content. In System Sciences, 2007. HICSS 2007. 40th Annual Hawaii International Conference on (pp. 51-51). IEEE.

Cullen, J. (2005). Mobile TV-the next step for mobile. Journal of the Communications Network, 4, 85-89.

Engineering News, (2013) Opportunities for Africa Emerge Despite, DTT delays, http//www.engineeringnews.co.za/.../opportunities-forafrica-emerge; [Online] Available 15/04/2013.

Hazel Kwon, Kyounghee, and Bum Soo Chon. "Social influences on terrestrial and satellite mobile-TV adoption in Korea: Affiliation, positive self-image, and perceived popularity." The International Journal on Media Management 11.2 (2009): 49-60.

Hsu, C. H., \& Hefeeda, M. (2009, January). Bounding switching delay in mobile TV broadcast networks. In IS\&T/SPIE Electronic Imaging (pp. 72530A-72530A). International Society for Optics and Photonics.

Knoche, H., McCarthy, J. D., \& Sasse, M. A. (2005, November). Can small be beautiful?: assessing image resolution requirements for mobile TV. In Proceedings of the 13th annual ACM international conference on Multimedia (pp. 829-838). ACM.

Lenth, R. V. (2001). Some practical guidelines for effective sample size determination. The American Statistician, 55(3), $187-193$.

Malhotra, N., \& Birks, D. (2007). Marketing Research: an applied approach: 3rd European Edition. Pearson Education.

Marcus, A., Roibás, A. C., \& Sala, R. (2010). Mobile TV: Customizing Content and Experience. Springer.

Multichoice (2013) DStv Mobile: [Online] Available http//www.multichoice.co.za/ (14 April 2013)

Shim, J. P., Ahn, K., \& Shim, J. M. (2006). Empirical findings on the perceived use of digital multimedia broadcasting mobile phone services. Industrial Management \& Data Systems, 106(2), 155-171.

Varnali, K., \& Toker, A. (2010). Mobile marketing research: The-state-of-the-art. International Journal of Information Management, 30(2), 144-151.

Venkatesh, V., \& Davis, F. D. (2000). A theoretical extension of the technology acceptance model: four longitudinal field studies. Management science, 46(2), 186-204. 